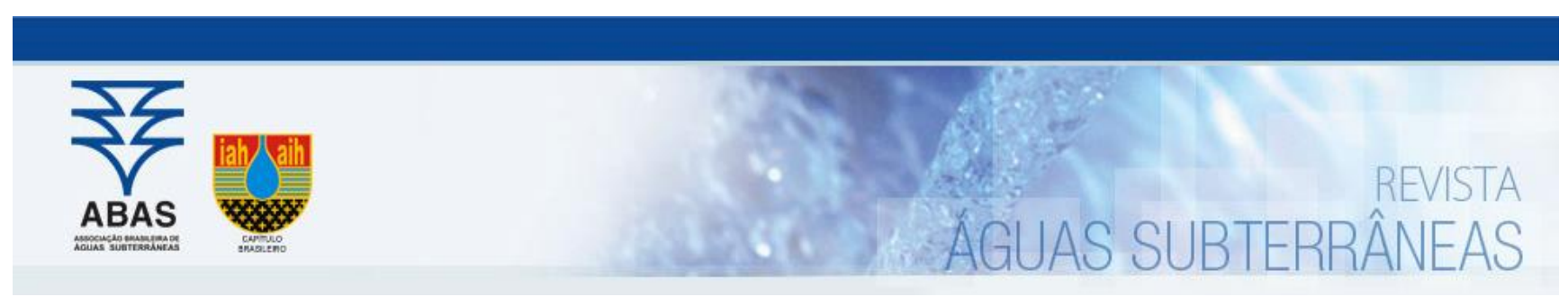

Artigos

\title{
Análise de Favorabilidade para Exploração de Água Subterrânea em Aquífero Costeiro, Estado do Maranhão
}

\section{Analysis of Favorability for Groundwater Exploration in Coastal Aquifer, Maranhão State}

\author{
Caetano Pontes Costanzo1; Alexandre Campane Vidal2 ${ }^{\bowtie}$ \\ 1 Walm Engenharia e Tecnologia Ambiental Ltda. Departamento de Hidrogeologia e Gestão de Áreas Contaminadas. São Paulo, \\ SP. \\ 2 Universidade Estadual de Campinas. Departamento de Geologia e Recursos Naturais (UNICAMP.DGRN), Campinas, SP.
}

$\triangle$ caetano.costanzo@gmail.com, acvidal@gmail.com

Palavras-chave:

Exploração das águas subterrâneas. Litologia e capacidade específica.

\section{Resumo}

Esta pesquisa aplica a análise de favorabilidade para a exploração de águas subterrâneas, visando à diminuição do risco exploratório em função, principalmente, das características da rocha reservatório em região costeira. 0 estudo foi elaborado com dados de litologia, vazão, nível estático e nível dinâmico de poços instalados próximos à cidade de São Luís / MA em área portuária / industrial. A área alvo foi escolhida devido à complexidade geológica e a proximidade com o mar, que acarretam baixa previsibilidade no comportamento hidrodinâmico antes dos projetos de perfuração, além de ser demandante de altas vazões de água subterrânea. As áreas com valores de capacidade específica superiores a $1,0 \mathrm{~m} 3 / \mathrm{h} / \mathrm{m}$ foram consideradas produtivas. Os resultados encontrados limitaram três principais áreas (norte centro-leste e sudoeste) com maiores potenciais de exploração em função dos dados disponíveis de descrição litológica e vazão. Além disso, o maior valor de contraste encontrado na pesquisa $(4,98)$ esteve associado à variável porcentagem de arenitos, o que demonstra ser esta variável um fator importante para o potencial exploratório do aquífero nesta área.

Abstract

Keywords:

Favorability analysis has been applied as a method to reduce the exploration risk in groundwater exploration due mainly, to the characteristics of reservoir rock in coastal aquifer. The research has been elaborated with well hydraulics data and lithology from wells located near the city of São Luís / MA. The target area was chosen because of the geological complexity and proximity to the sea, which leads to a low predictability in hydrodynamic behavior before drilling projects. Areas with specific capacity values above $1.0 \mathrm{~m} 3 / \mathrm{h} / \mathrm{m}$ were considered productive. The results limited three areas (north, east-center and south-west) with higher exploitation potentials due to the available data. In addition, the highest contrast value found in the research (4.98) was associated with the variable percentage of sandstones, which demonstrates that this variable is an important factor for the exploratory potential of the aquifer in this area.

\section{INTRODUÇÃO}

A principal deficiência para a gestão adequada dos aquíferos costeiros brasileiros é a carência de dados básicos sobre a favorabilidade hídrica e seu potencial de exploração, o que dificulta a elaboração de planos de gestão atual e futura (HIRATA et al., 2010).

A boa gestão dos recursos hídricos subterrâneos está essencialmente associada à escolha dos principais fatores que causam uma vazão sustentável nos poços, bem como a delimitação de áreas com características semelhantes de fluxo do aquífero. Em áreas costeiras, pouco exploradas e com baixa densidade de informação, o conhecimento destes fatores torna-se fundamental (MADRUCCI, 2004).
Neste sentido, o sucesso na exploração está associado ao grande número de variáveis, relacionadas a fatores geológicos. Partes dessas informações são dependentes do método e qualidade do equipamento de perfuração, do perfil construtivo e da finalidade de construção de determinado poço (VIDAL et al., 2006)

Portanto, a abordagem quantitativa em relação às principais características deste aquífero, bem como à sua gestão, pode ser realizada por meio de análises estatísticas das principais variáveis relacionadas aos fatores geológicos e de dinâmica hidrogeológica.

Técnicas estatísticas para avaliar a favorabilidade de potenciais reservatórios e recursos naturais têm sido aplicadas por 
diversos autores como, Bonham-Carter (1994), Rostirolla (1997), Raines (1999), Araújo \& Macedo (2002), Harris et al. (2003), Vidal et al. (2006), e Madrucci et al. (2008).

A análise de favorabilidade, ao invés de interpretar de forma isolada cada variável amostrada, permite que os atributos georeferenciados sejam discretizados em células e correlacionados espacialmente, resultando em mapas de favorabilidade (VIDAL et al., 2006).

A combinação das informações utilizadas pela análise de favorabilidade é realizada pela aplicação da probabilidade bayesiana, utilizada para determinar a correlação espacial entre um evento e fatores relacionados a um conjunto de pesos, sendo um peso definido para cada classe de fator (LEE, KIM \& $\mathrm{OH}, 2012)$.

A carência de informações de subsuperfície e as incertezas quanto à distribuição das diferentes características litológicas e hidráulicas motivaram a escolha do aquífero costeiro Itapecuru para o desenvolvimento deste trabalho.

Além disso, a região de pesquisa é uma área portuária e industrial deficitária em relação à demanda de água. A água subterrânea é utilizada tanto para as atividades operacionais do Porto como também para uma usina de Pelotização, com consumo de $4.934 \mathrm{~m}^{3} / \mathrm{dia}$, que representam $52 \%$ do consumo diário total de água (VALE, 2012). Esta demanda é crescente e, consequentemente, novos poços de captação serão necessários para a oferta de água.
Dessa forma, o principal objetivo deste estudo é avaliar potenciais áreas para exploração das águas subterrâneas associadas ao aquífero Itapecuru.

Portanto, foi utilizada a análise de favorabilidade a fim de permitir uma melhor gestão deste recurso hídrico, bem como aumentar as possibilidades de oferta de água para a região.

\section{2. ÁREA DE ESTUDO}

A área de estudo é o Complexo de Ponta da Madeira situado no município de São Luís, na margem leste da Baía de São Marcos, no Estado do Maranhão, nordeste do Brasil. A Figura 1 ilustra a localização geográfica da área de pesquisa.

Os principais rios que cortam a região são o Bacanga e o Anil (SANTOS \& LEAL, 2013), sendo que a área de estudo encontra-se no centro de um sistema de golfo, com variações médias de maré de $4 \mathrm{~m}$ e máxima superior a $7 \mathrm{~m}$ (TEIXEIRA \& SOUZA FILHO, 2009).

No contexto geológico, a área de pesquisa está localizada na Bacia de São Luís que, junto com as bacias Ilha Nova e Barreirinhas, formam um sistema de grábens profundos, limitados por falhas normais orientadas na direção NW-SE (ALMEIDA, 1967).

A Bacia de São Luís possui coluna sedimentar que atinge espessura de $5.000 \mathrm{~m}$, dos quais $2.500 \mathrm{~m}$ correspondem ao intervalo Mesozoico (Cretáceo) e o intervalo restante ao Cenozóico (ALMEIDA, BRITO NEVES \& FUCK, 1977).

Figura 1 - Localização da área de estudo (contorno em vermelho)

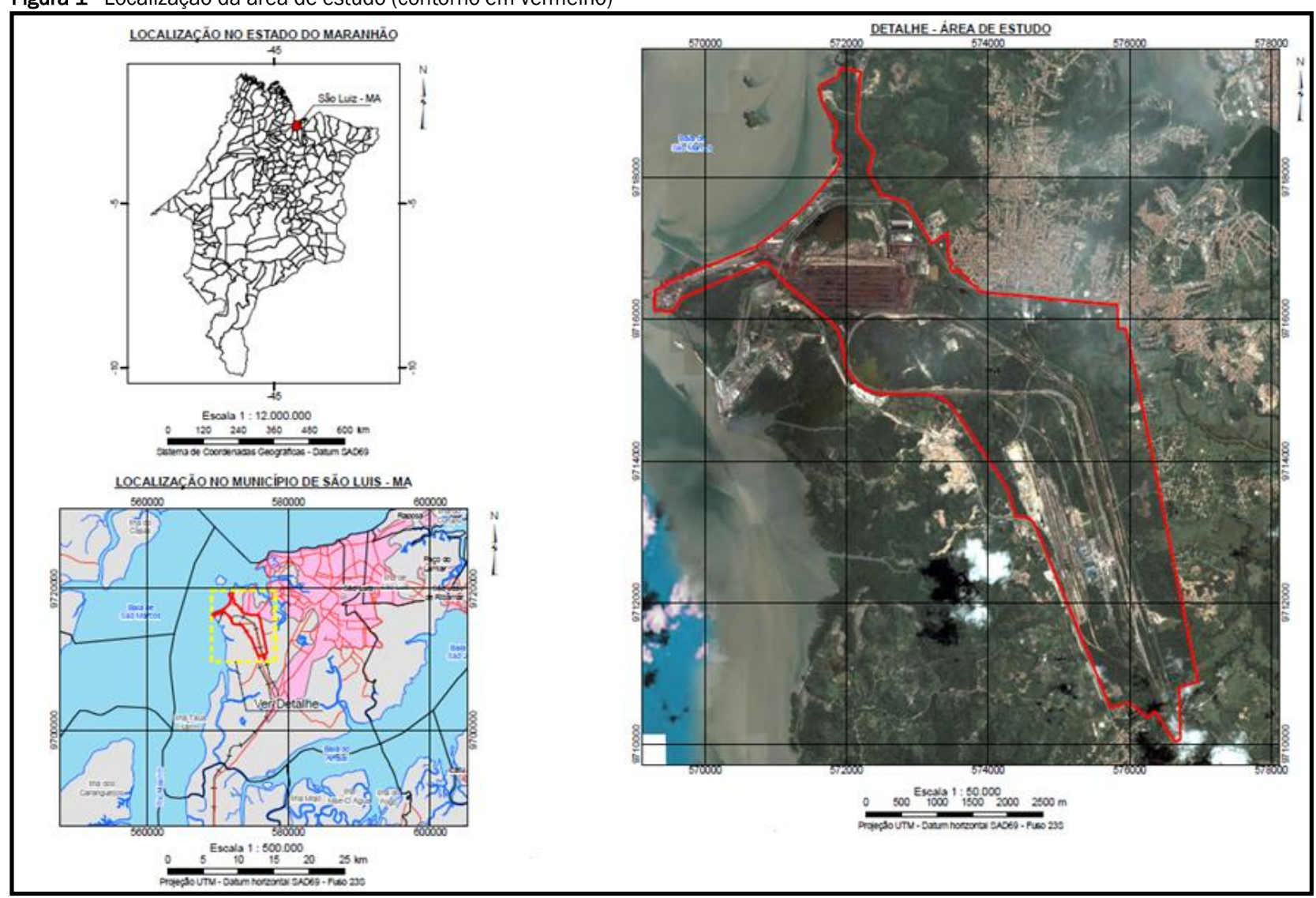


Com relação à geologia local, conforme Klein et al., 2012, as principais unidades hidroestratigráficas da área de pesquisa são:

- Unidade de Aluviões;

- Unidade de sedimentos Terciários do Grupo Barreiras;

- Unidade de sedimentos do Terciário Paleógeno;

- Unidade de materiais do Grupo Itapecuru, do Cretáceo;

- Unidade de embasamento cristalino formado por rochas graníticas, até o momento não encontrado na ilha do Maranhão.

O aquífero pesquisado neste trabalho é o Itapecuru. O Grupo Itapecuru é constituída por areias de coloração laranja, com granulometria média a grossa, muito argilosas, com intercalações de argila e silte e estratificações plano-paralelas. Seu potencial hidrogeológico é classificado como satisfatório para poços com demanda de vazão inferior a $40 \mathrm{~m}^{3} / \mathrm{h}$ e até $200 \mathrm{~m}$ de profundidade (KLEIN, 2012).

Os afloramentos deste Grupo são observados na Ponta da Madeira e no Farol de São Marcos, no município de São Luís. A espessura média investigada deste aquífero é de $80 \mathrm{~m}$, mas atinge possivelmente profundidades bem maiores até o embasamento cristalino que, segundo dados de Klein (2012), ocorre a cerca de $1.250 \mathrm{~m}$ de profundidade.

\section{MÉTODOS}

O fluxo de trabalho adotado nesta pesquisa apresenta a se

guinte ordem: (i) aquisição de dados de campo oriundos de um projeto da empresa WALM Engenharia e Tecnologia Ambiental Ltda. (WALM, 2012) (descrições de testemunhos de sondagens, dados de vazão, nível estático e nível dinâmico de poços de monitoramento, piezômetros e poços de captação); (ii) elaboração do modelo geológico 3D a partir de métodos geoestatísticos; (iii) definição de áreas produtivas de água subterrânea; (iv) elaboração de mapa de favorabilidade.

\subsection{Base de dados}

A base de dados utilizada refere-se às informações geológicas advindas das descrições de testemunhos de sondagens de 26 poços instalados na área. Além dessas informações, foram utilizados dados de vazão, nível estático e nível dinâmico de 14 poços dentre os 26 presentes na área. A Figura 2 exibe a localização destes 26 poços utilizados na pesquisa.

Figura 2 - Mapa com a localização dos poços utilizados (pontos vermelhos - piezômetros e poços de monitoramento; pontos pretos - poços de captação). sad69 - complexo de ponta da madeira / São Luís - MA

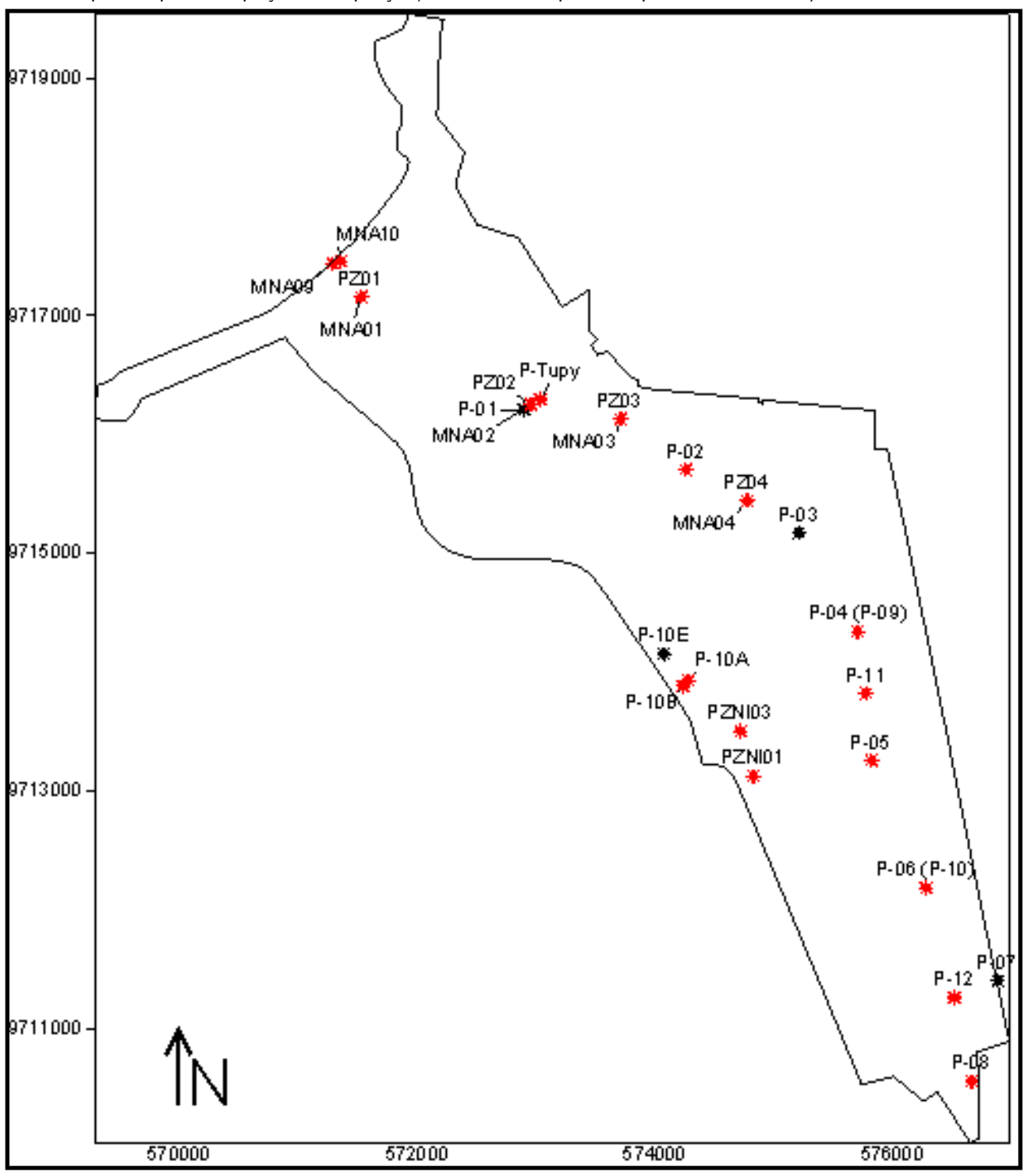


A descrição litológica total corresponde à informação de 2.869 metros referentes aos perfis litoestratigráficos de 26 poços. Os diferentes tipos litológicos foram agrupados em três principais classes: (i) rochas argilosas; (ii) rochas referentes aos sedimentos do Paleógeno (Grupo Barreiras) e (iii) sedimentos mais antigos do Grupo Itapecuru.

Buscando uma classificação voltada às propriedades de aquífero, os grupos litológicos foram agrupados em duas classes: (i) "arenitos" e (ii) "argilitos", visto que representam as litologias que condicionam o fluxo subterrâneo e o potencial de reservatórios de água.

Os poços apresentam profundidade média de $110 \mathrm{~m}$, com profundidade mínima de $56 \mathrm{~m}$ e máxima de $167 \mathrm{~m}$ (Figura 3). As profundidades mínima e máxima comprovam que o aquífero pesquisado é o Itapecuru.

Figura 3 - Profundidade dos poços na área de pesquisa - Complexo de Ponta da Madeira / São Luís - MA.

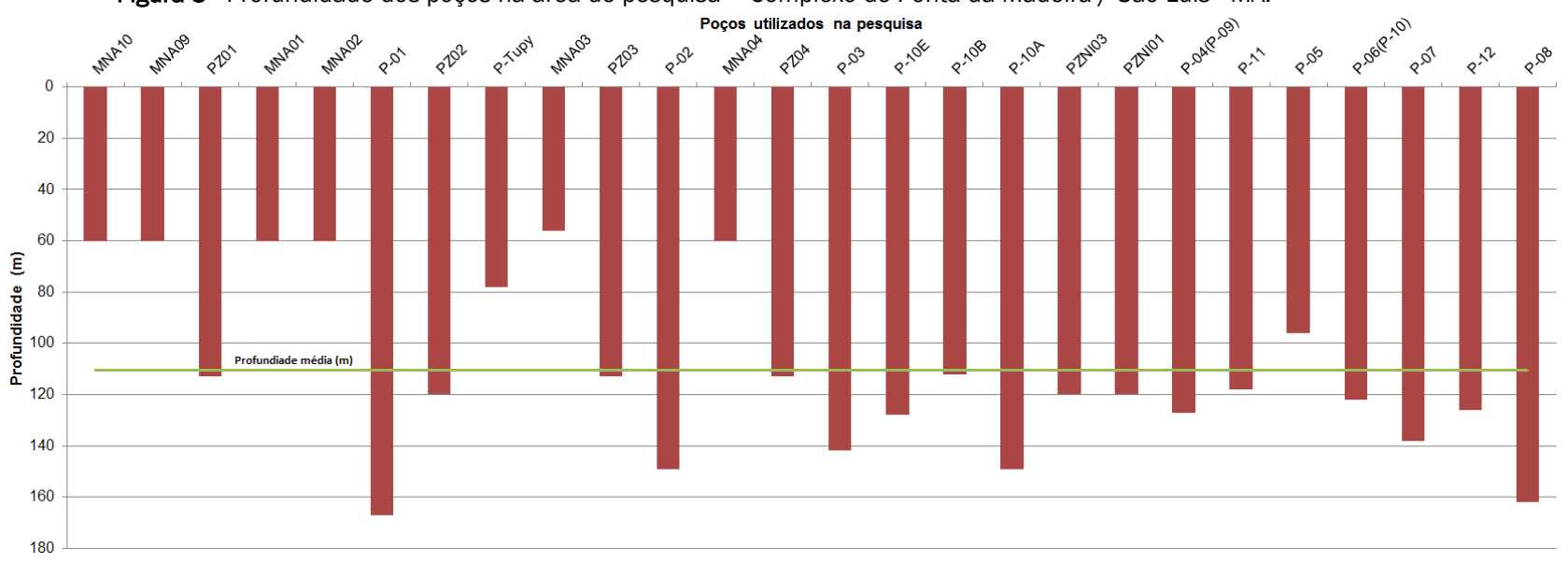

De acordo com a Figura 2, observam-se vários poços alinhados, como exemplo, os seis poços na borda leste da área ( $P$ 04, P-11, P-05, P-06, P-12 e P-8) estão posicionados em uma linha norte sul. No entanto, de forma geral os poços estão distribuídos por toda área, sendo algumas áreas cobertas de informação. Logo, os poços alinhados não interferem nos métodos utilizados nesta pesquisa.

A porção central da área é coberta por vários poços, enquanto que as bordas da área nas porções sudoeste e, principalmente, a norte e noroeste apresentam ausência de informa- ções. Outro ponto a se destacar é a presença de poços posicionados bem próximos um ao outro, aumentando a incerteza espacial da informação de subsuperfície, associada às descrições litológicas dos poços.

As descrições geológicas descrevem as litologias conforme granulação da rocha sedimentar, alguns apenas por diferenciação de cor e pela associação de duas classes de granulação. Por isso, foi adotada a litologia predominante (arenitos e argilitos), com base na granulação do sedimento, para a definição dos tipos litológicos, conforme exibe a Tabela 1.

Tabela1 - Grupos associados às rochas descritas nos poços

\begin{tabular}{ccc}
\hline Grupos & Litologia & Porcentagem \\
\hline Arenitos $(47,2 \%)$ & Arenito & $4,7 \%$ \\
& Arenito grosso & $2,0 \%$ \\
& Arenito fino & $14,0 \%$ \\
& Arenito muito fino & $16,7 \%$ \\
& Arenito Argiloso & $2,6 \%$ \\
Argilas (52,8\%) & Arenito Siltoso & $7,2 \%$ \\
& & $48 \%$ \\
& Argilito & $3,3 \%$ \\
& Siltito & $1,5 \%$ \\
\hline
\end{tabular}

\subsection{Elaboração do modelo geológico 3D por meio de métodos estatísticos}

A malha para a geração do modelo geológico corresponde a 1.710.000 células, com 150 células no eixo $x, 150$ no eixo $y$ e 76 em z, e as dimensões de $53,64 \mathrm{~m}, 65,87 \mathrm{~m}$ e $2,5 \mathrm{~m}$, respectivamente. Tais dimensões foram definidas de acordo com o tamanho da área de estudo e profundidade dos poços.

O método geoestatístico aplicado para a geração do modelo geológico 3D foi a krigagem por indicatriz (JOURNEL, 1984).
Para auxiliar na criação do modelo, foi utilizado o software SGeMS - Stanford Geostatistical Modeling Software (REMY et al., 2004). A krigagem por indicatriz é aplicada a variáveis discretas e, neste caso, foi aplicada para a determinação apenas da litologia.

A krigagem por indicatriz serve para produzir a predição de valores sobre uma superfície ou volume e, sobretudo, para gerar modelos de incertezas locais para dados geográficos que compartilham uma base de informações (FELGUEIRAS, DRUCK \& MONTEIRO, 2002). 
Esta krigagem compreende um tipo não linear, que se utiliza da posição de valores dos dados para gerar uma distribuição local em vez de uma distribuição global das propriedades analisadas (GOOVAERTS, 1997).

A técnica tem como etapa inicial a transformação binária dos dados. Desta maneira, são geradas as variáveis indicatrizes $\left(I_{(x)}\right)$. Dado um conjunto $X$ e o complementar $X c$, no domínio $A=X \cup X^{c}$, onde há amostras $\mathrm{x}_{\mathrm{i}}$ localizadas em A com $\mathrm{i}=1$, ..., n. A variável indicatriz $I\left(\mathrm{x}_{\mathrm{i}}\right)$ é dada por:

$I\left(x_{i}\right)=1, \operatorname{sex}_{i} \in X=0, \operatorname{sex}_{i} \in X^{c}$,

onde $X$ é um conjunto do domínio $\mathrm{A}$ e $\mathrm{Xc}$ o conjunto complementar de $X$.

A condição leva a um quadro onde os valores assumidos a cada conjunto e em cada ponto amostral pertençam a 0 ou 1. Posterior à definição das variáveis indicatrizes, realizam-se procedimentos similares ao utilizado na krigagem ordinária.

Após ajuste dos variogramas para cada litologia e a definição do raio de pesquisa, foi realizada a estimativa do modelo de distribuição das fácies. Para evitar erros de estimativa, as células da malha fora da área de interesse foram consideradas nulas, como também em porções com baixa densidade de informação.

\subsection{Análise de favorabilidade}

A etapa inicial da avaliação corresponde à geração do modelo de ocorrência, quando são discriminadas as evidências favoráveis à concentração (critérios diagnósticos). A segunda etapa consiste na geração de um modelo de probabilidade, estruturado segundo o modo de ocorrência. Assim, é possível predizer a favorabilidade de um depósito mineral, de tamanho e volume adequados, ocorrer em determinada área alvo.

Seguindo as premissas presentes em Rostirolla (1997), são consideradas "necessárias" aquelas variáveis que sempre existem associadas aos depósitos conhecidos, enquanto as variáveis "suficientes" podem ou não existir, mas a sua presença representa um forte indício de ocorrência do depósito.

A condição de suficiência de uma variável E é satisfeita quando a probabilidade de existência do depósito (hipótese H) é maximizada com a presença da variável $(\mathrm{P}(\mathrm{H} \mid \mathrm{E})=$ máximo). A condição de necessidade da variável é satisfeita quando a probabilidade de não existência do depósito é maximizada com a ausência desta variável.

Nos mapas de variáveis exploratórias, os pontos conhecidos (amostras da população estudada) são tratados como pixels e estimados espacialmente. A probabilidade condicional é obtida através do número de pixels da variável inserido na área produtiva, em relação ao número total de pixels existente da variável.

Segundo o modelo adotado por Bonham-Carter (1994), em todas as células avaliadas, a chance posterior $\mathrm{Ch}(\mathrm{H} \mid \mathrm{Ejk})$ de ser encontrado um reservatório (ou hipótese $\mathrm{H}$ ) é dada pelo somatório da chance prévia $\mathrm{Ch}(\mathrm{H})$, obtida da razão entre o número de pixels da área produtiva pelo número de pixels da área de estudo, com os ponderadores $\mathrm{w}_{\mathrm{j}}^{\mathrm{k}}$ referentes às evidências $E_{j}$ : $\ln C h\left(H \mid E_{j}^{k}\right)=w_{j}^{k}+\ln C h(H)$

onde o índice superior $k$ refere-se à presença $(+)$ ou ausência (-) da variável em relação ao depósito, e os ponderadores $\mathrm{Wj}_{\mathrm{j}}^{\mathrm{k}}$ são razões de probabilidade calculados do seguinte modo para cada variável $\mathrm{E}_{\mathrm{j}}$ :

$w_{j}^{k}=\ln \frac{P\left(E_{j}^{k} \mid H\right)}{P\left(E_{j}^{k} \mid \bar{H}\right)}=\ln \frac{\frac{H \cap E_{j}^{k}}{\frac{H}{H \cap E_{j}^{k}}}}{\frac{\bar{H}}{n^{\prime}}}$

Todos os níveis georreferenciados adicionais devem ser computados como mapas binários e, para $\operatorname{Ej}(\mathrm{j}=1,2,3, \ldots \mathrm{n}$ ) mapas, o somatório é representado pela fórmula:

$\operatorname{Ch}\left(H \mid E_{1}^{k} \cap E_{2}^{k} \cap . . E_{n}^{k}\right)=\exp \left\{\sum_{j=1}^{n} w_{j}^{k}+\ln C h(H)\right\}$

Baseado nos resultados, a probabilidade posterior (ou favorabilidade para cada célula avaliada) pode ser obtida a partir da chance posterior.

Dessa forma, a análise conduzida pelos dados (análise bayesiana), após definido o modelo geológico, selecionam-se os mapas de evidência e calculam-se os pesos de evidência ( $w+$ e w-) para cada classe dos mapas temáticos. Após isso, definem-se os fatores positivos à ocorrência de água subterrânea e elaboram-se mapas binários os quais são atribuídos os pesos w+e w-.

A partir dos mapas binários, realiza-se o teste de independência condicional e por fim, elabora-se o mapa de favorabilidade (mapa de probabilidade posterior), por meio da probabilidade prévia de ocorrência e nos pesos de evidência ( $w+$ e $w-)$ de cada mapa envolvido na análise (MADRUCCl et al., 2008).

\subsubsection{Análise de favorabilidade no aquífero costeiro}

Como os poços de captação são construídos para diferentes finalidades, a exploração de água subterrânea, diferente dos depósitos mineralizados, não apresenta um valor de teor de corte (cut off) para um poço se tornar economicamente viável. Por exemplo, uma vazão de $10 \mathrm{~m}^{3} / \mathrm{h}$ pode ser inviável para o abastecimento público de uma cidade, porém útil para uma propriedade rural.

Dessa forma, como não há limites estabelecidos para a definição do teor de corte, este valor, para esta pesquisa, foi determinado a partir das medidas estatísticas da distribuição da variável capacidade específica de 14 poços da base de dados (Tabela 2).

No presente trabalho, as variáveis utilizadas para a análise de favorabilidade correspondem aos mapas gerados no modelo geológico 3D, ou seja, (1) porcentagem de arenitos, (2) espessura de arenitos (Figura 4) e a (3) média das probabilidades de ocorrência de arenitos.

Métodos convencionais de interpolação foram utilizados para a determinação do mapa de espessura de arenitos e porcentagem de arenitos definidos com a utilização das informações dos poços. 0 mapa de espessura de arenitos ilustra espessuras superiores a $30 \mathrm{~m}$ em grande parte da área. Ao analisar a porcentagem de arenitos em relação às argilas, a área sul apresenta as menores porcentagens, enquanto a área centronorte as maiores. 
Para a aplicação da análise de favorabilidade na exploração do aquífero costeiro, foram adotadas como condições de sucesso as áreas de maior produtividade nos poços da base de dados, verificadas por meio dos valores de capacidade específica (obtidas quando a vazão é dividida pela diferença entre o nível dinâmico e o nível estático). Esta medida corresponde à quantidade de água retirada do poço por unidade de tempo e de rebaixamento (FREEZE \& CHERRY, 2017).

A Tabela 2 contempla os dados de capacidade específica $\left(\mathrm{m}^{3} / \mathrm{h} / \mathrm{m}\right)$ utilizados para a definição de áreas produtivas pela análise de favorabilidade.

Figura 4 - Mapas de espessura e porcentagem de arenitos utilizados na análise de favorabilidade

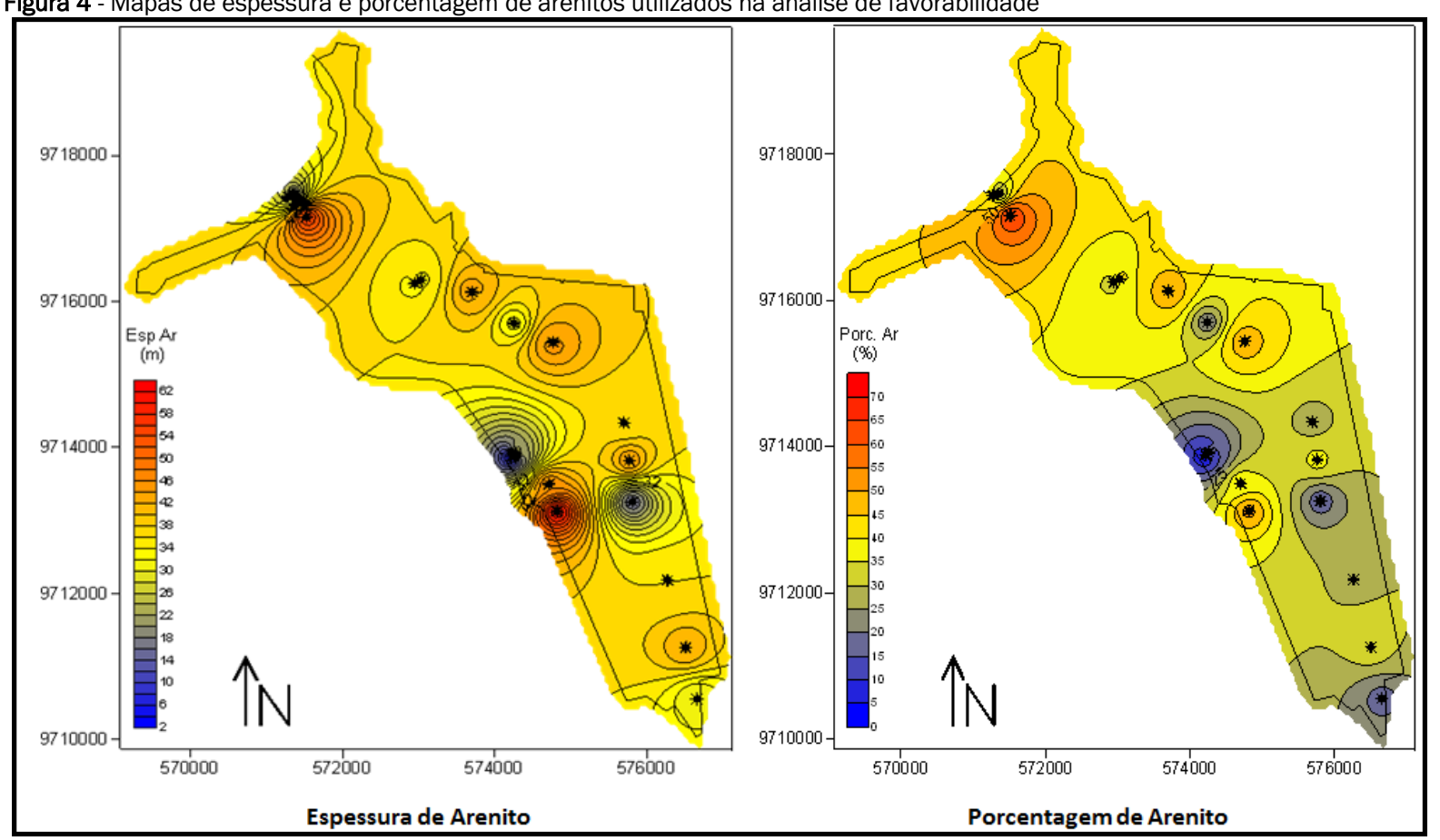

Tabela 2 - Valores de capacidade específica $\left(\mathrm{m}^{3} / \mathrm{h} / \mathrm{m}\right)$ utilizados para a definição de áreas produtivas pela análise de favorabilidade

\begin{tabular}{cccccc} 
*Poço & Q $\left(\mathrm{m}^{3} / \mathrm{h}\right)$ & Profundidade $(\mathrm{m})$ & Nível estático $(\mathrm{m})$ & Nível dinâmico $(\mathrm{m})$ & Capacidade específica $\left(\mathrm{Q} / \mathrm{ND}-\mathrm{NE}-\mathrm{m}^{3} / \mathrm{h} / \mathrm{m}\right)$ \\
\hline PZ01 & 8,00 & 113,00 & 16,00 & 19,00 & 2,67 \\
PZ02 & 4,90 & 120,00 & 32,15 & 33,40 & 3,92 \\
PZ03 & 17,00 & 113,00 & 46,10 & 59,00 & 1,32 \\
PZ04 & 9,00 & 113,00 & 32,20 & 35,45 & 2,77 \\
PZNI01 & 5,66 & 120,00 & 36,15 & 39,15 & 1,89 \\
PZNI03 & 3,60 & 120,00 & 34,40 & 38,45 & 0,89 \\
P-01 & 4,19 & 167,00 & 31,46 & 44,05 & 0,33 \\
P-02 & 1,67 & 149,00 & 31,83 & 66,80 & 0,05 \\
P-03 & 3,44 & 142,00 & 35,06 & 55,98 & 0,16 \\
P-06 (P-10) & 2,43 & 122,00 & 34,30 & 56,10 & 0,11 \\
P-07 & 2,56 & 138,00 & 13,83 & 30,97 & 0,15 \\
P-08 & 3,06 & 162,00 & 26,50 & 43,35 & 0,18 \\
P-10B & 2,56 & 112,20 & 24,10 & 49,84 & 0,10 \\
P-10E & 1,49 & 128,00 & 25,70 & 44,06 & 0,08 \\
\hline
\end{tabular}

Fonte: WALM (2012)

*Dos 26 poços utilizados da base de dados, 14 apresentam dados de vazão, nível estático e nível dinâmico

A capacidade específica é influenciada pelas características físicas do reservatório, traduzida essencialmente pela transmissividade do aquífero. Nesta pesquisa, a incerteza associada à variável capacidade específica não será analisada.

\section{RESULTADO E DISCUSSÃO}

\subsection{Modelo geológico 3D}

O modelo geológico foi limitado próximo à superfície do ter- reno. Embora posicionado próximo à região costeira, a variação da cota altimétrica é significativa, ao nível do mar na porção norte da área e atingindo cota máxima de $45 \mathrm{~m}$ em alguns pontos do mapa (Figura 5). Os valores de profundidades dos poços foram convertidos conforme os valores de cota do terreno e posicionados na malha do modelo. 
Figura 5 - A: Mapa de cota do terreno utilizado como limite superior do modelo. B: Vista lateral com a superfície do terreno e posicionamento dos poços utilizados na pesquisa

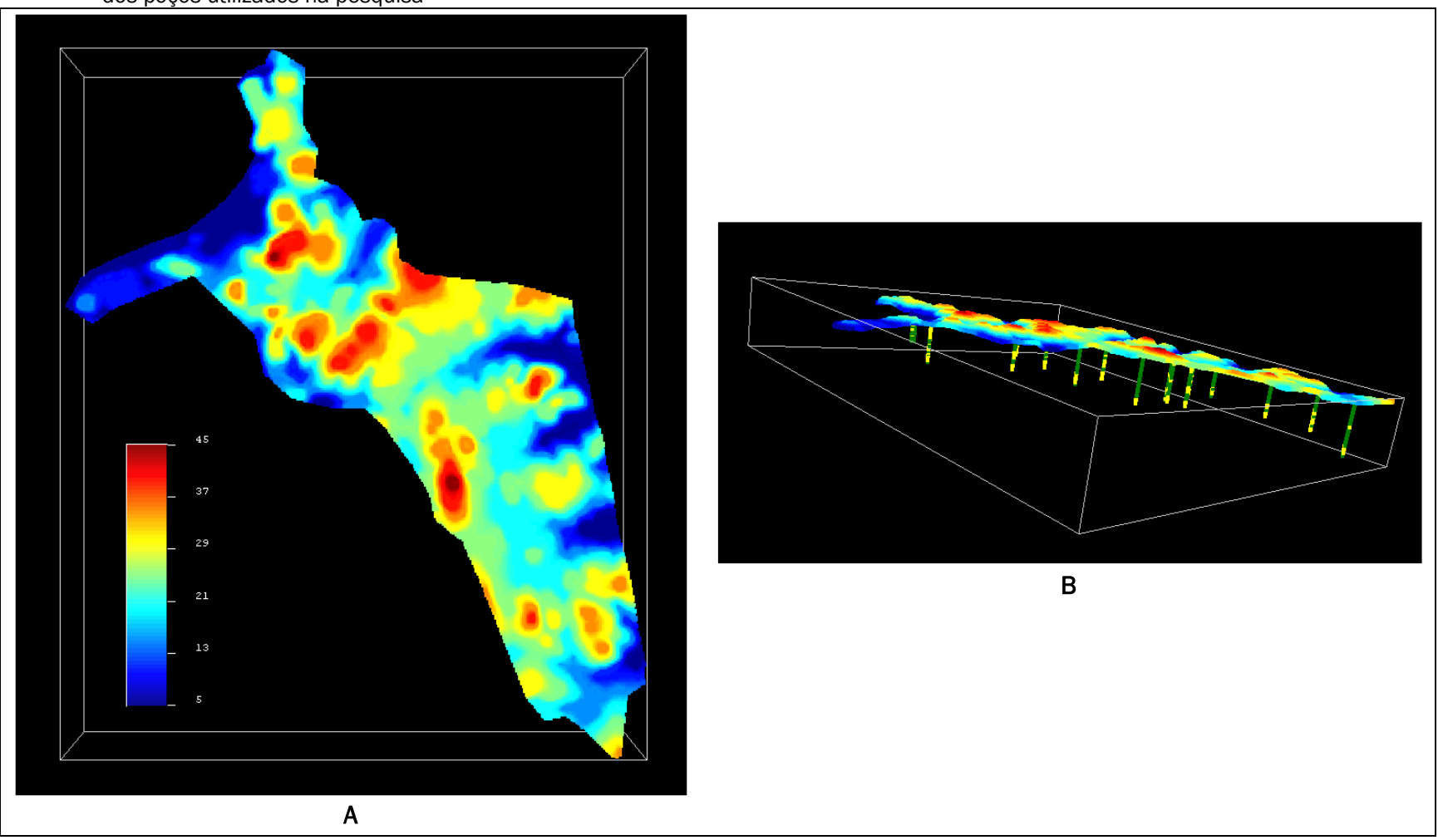

Conforme mencionado no Item 3.1, a determinação dos dois grupos litológicos (arenitos e argilitos) foi baseada na granulação, sendo o grau de seleção outro critério para a subdivisão dos arenitos, assumindo a correlação entre esses dois parâmetros com porosidade e permeabilidade, respectivamente.

Os variogramas apresentaram baixa continuidade espacial para os dois grupos litológicos, indicando que na área não há tendência de aumento nos valores para cada litologia, podendo ser considerada constante a distribuição na área.

Os resultados da krigagem indicatriz apresentam valores entre 0 e 1, correspondendo à probabilidade de ocorrência da variável arenito, para cada célula da malha de pesquisa ( $\mathrm{Fi}$ gura 6). Os resultados estão apresentados para as profundidades de $82,5 \mathrm{~m}$ à $5 \mathrm{~m}$, com intervalos de $12,5 \mathrm{~m}$. A área sul apresenta as menores probabilidades para ocorrência de rochas reservatórios, enquanto que a centro-norte as maiores.

A krigagem indicatriz utiliza-se da média ponderada para o cálculo das informações desconhecidas nos pontos vizinhos. Caso todas as variáveis estimadas ultrapassem o limite fixado em regiões adjacentes, a técnica atribui uma alta probabilidade de ocorrência na região de interesse (LIU, JANG \& LIAO, 2004).

Atribuindo-se as possíveis variações de capacidade específica para as duas litologias mapeadas, a distribuição espacial da probabilidade de ocorrência de sedimentos arenosos, nos planos horizontal e vertical, possibilita a previsão das potenciais zonas de reservatórios de água a partir de dados litológicos.

Para a distribuição das probabilidades de ocorrência das rochas reservatórios em uma única malha, foi executada a junção, com base na seleção da litologia com maior probabilidade em cada célula da malha. 0 modelo estimado mantém a mesma proporção dos grupos de sedimentos em relação à proporção obtida pela descrição de campo dos poços.

A área central apresenta alta probabilidade para sete dos oito intervalos ilustrados. Para as maiores profundidades, grande parte da área apresenta condições favoráveis à ocorrência de arenitos.

A fim de quantificar a incerteza, foi possível representar a variável indicatriz por probabilidades de ocorrência. Neste caso foram representadas as probabilidades de 25\% (P25), 50\% (P50) e 75\% (P75). A estimativa de P25 seria a estimativa otimista na qual é determinado que todas as probabilidades superiores a $25 \%$ correspondem a arenitos e valores inferiores aos argilitos. 0 oposto ocorre para P75, que seria a estimativa pessimista.

A probabilidade média de ocorrência de arenitos seria a P50. Como esperado, em função dos dados de descrições de testemunhos de campo, a região central-norte e as porções mais profundas apresentam maiores áreas acima dos valores limites.

A média das probabilidades de todas as profundidades para cada cenário, P25, P50 e P75, pode sintetizar as probabilidades encontradas no modelo 3D (Figura 7). Estes três mapas da média das probabilidades foram utilizados para a análise de favorabilidade hidrogeológica que será discutida no Item 4.2.

Conforme as figuras geradas no modelo geológico 3D, a área norte apresenta elevado potencial de exploração. Na porção central é destacada a região leste também com possível potencial de captação de água subterrânea. Por fim a porção oeste da região sul apresenta bons valores de probabilidade de ocorrência de rocha reservatório. 
Figura 6 - Probabilidade da variável indicadora "arenito" para intervalos de profundidade em relação ao nível do mar

82,5

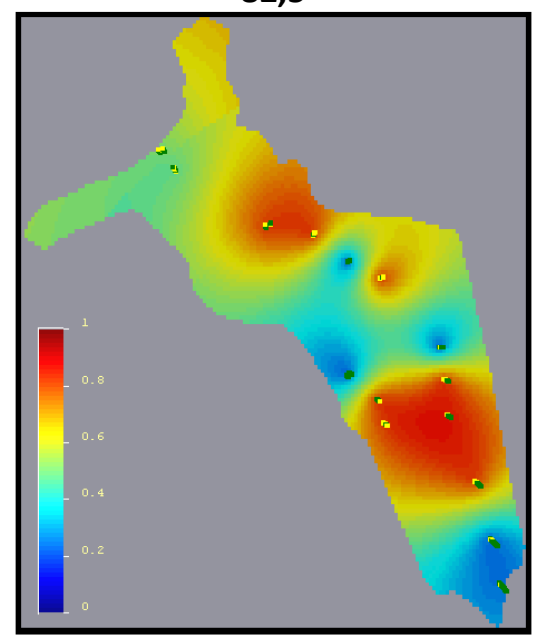

$45 \mathrm{~m}$

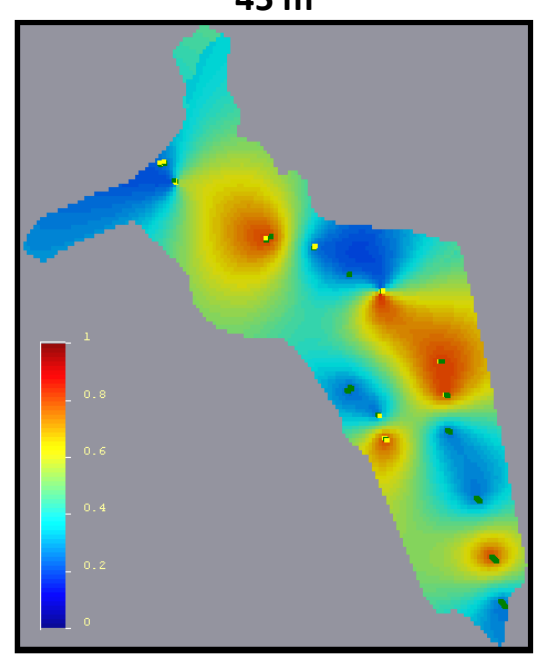

$7,5 \mathrm{~m}$

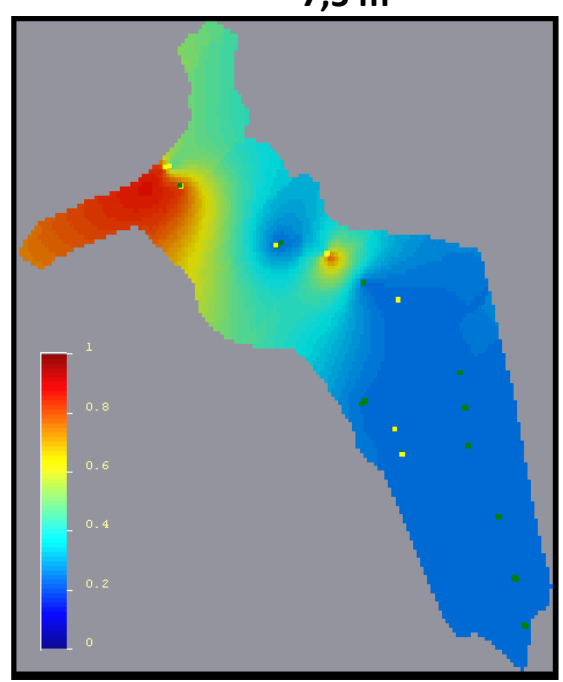

$70 \mathrm{~m}$

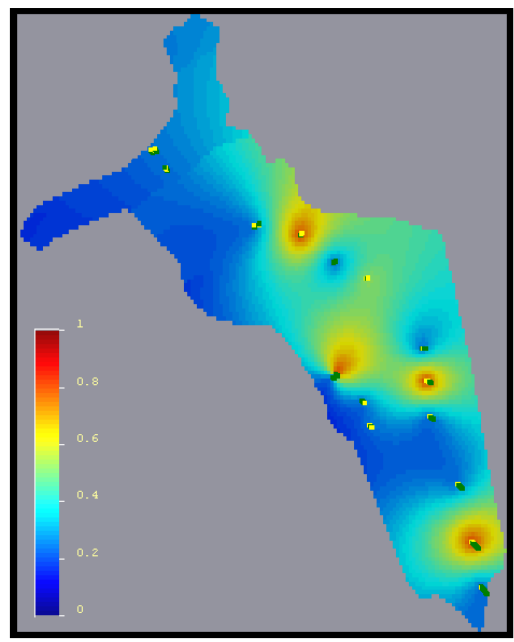

$32,5 \mathrm{~m}$
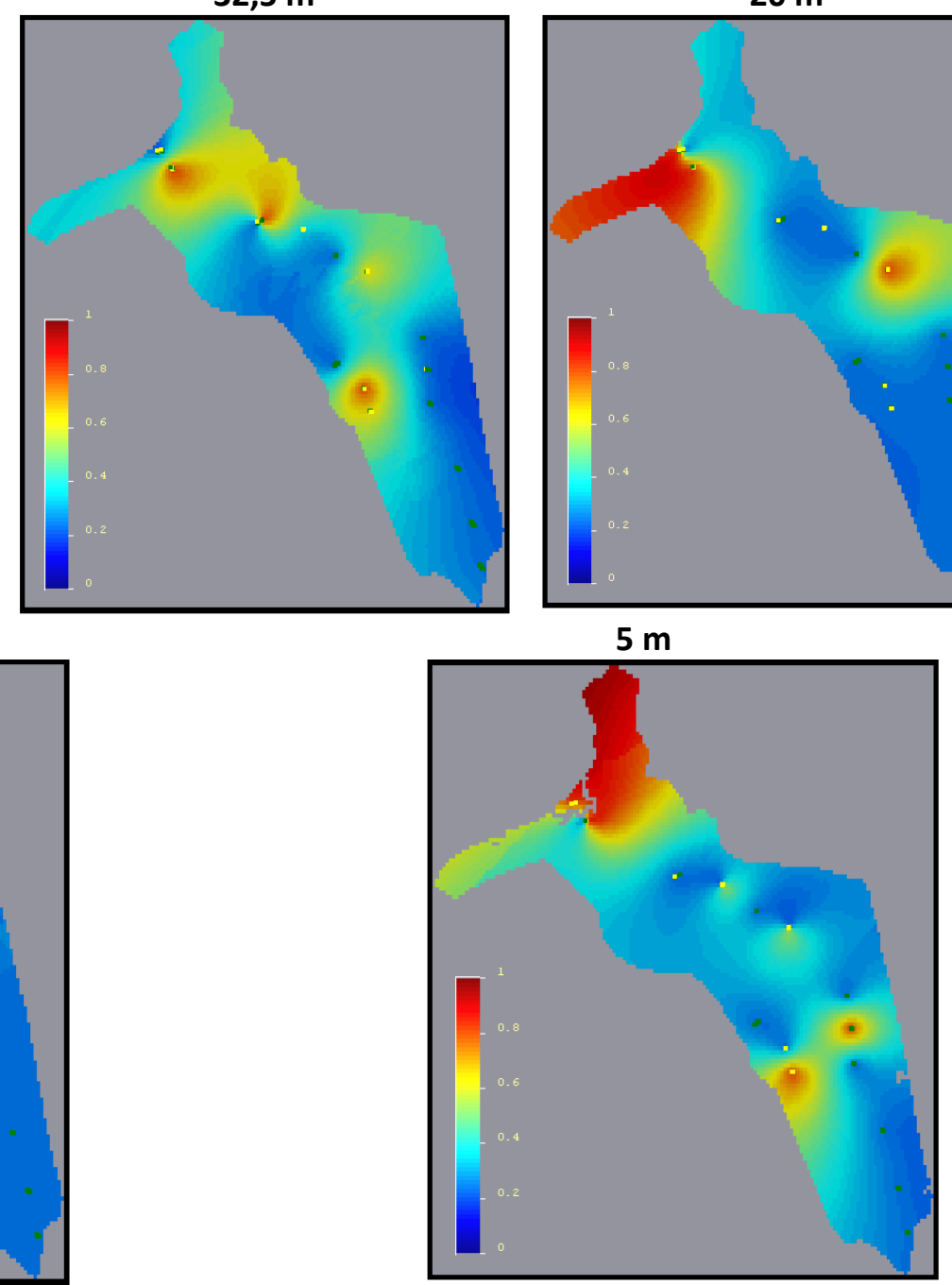

$57,5 \mathrm{~m}$

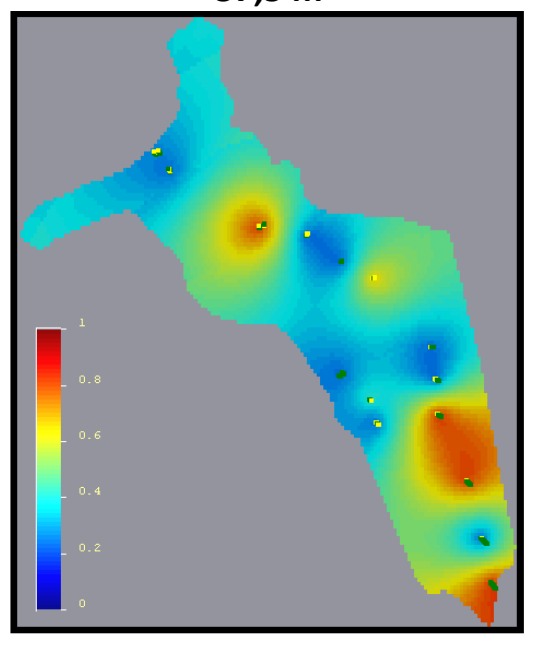

$20 \mathrm{~m}$

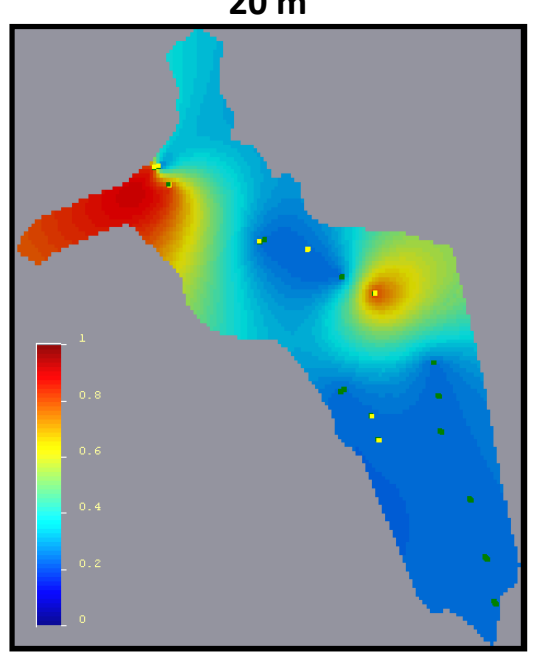

$5 \mathrm{~m}$ 
Figura 7 - Média das probabilidades para a ocorrência de arenitos no modelo geológico 3D

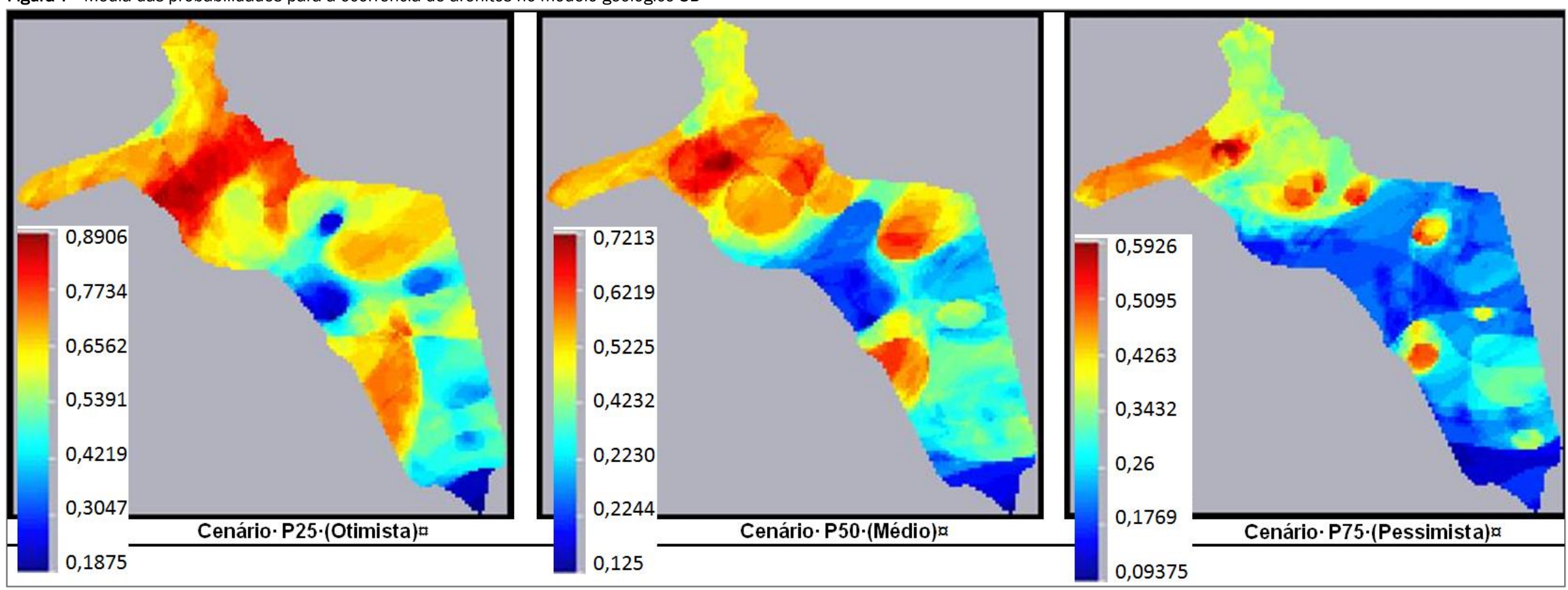




\subsection{Análise de favorabilidade}

\subsubsection{Definição de áreas produtivas}

A variável capacidade específica apresenta média de 1,04 $\mathrm{m}^{3} / \mathrm{h} / \mathrm{m}$, mediana de $0,26 \mathrm{~m}^{3} / \mathrm{h} / \mathrm{m}$ e variância de 1,63 . Para a definição das áreas definidas como produtivas, foi estabelecido valor de corte de $1,00 \mathrm{~m}^{3} / \mathrm{h} / \mathrm{m}$, que possui a maior frequência, como pode ser visto no histograma de função de probabilidade de massa na Figura 8.
Para a elaboração do mapa de áreas produtivas a partir dos dados de capacidade específica foi utilizado o método geoestatístico da krigagem como algoritmo interpolador. Dessa forma, preliminarmente, foi feita a análise variográfica que indicou como mais apropriado o variograma omnidirecional. 0 modelo de variograma foi do tipo esférico, com alcance de 8 $\mathrm{km}$ e patamar de 0,9. A krigagem utilizada foi a ordinária e o mapa final da área, com capacidade específica superior a 1 $\mathrm{m}^{3} / \mathrm{h} / \mathrm{m}$, configurou a "área mineralizada" (Figura 9).

Figura 8 - Histograma de função de probabilidade de massa para a variável capacidade específica da região de pesquisa

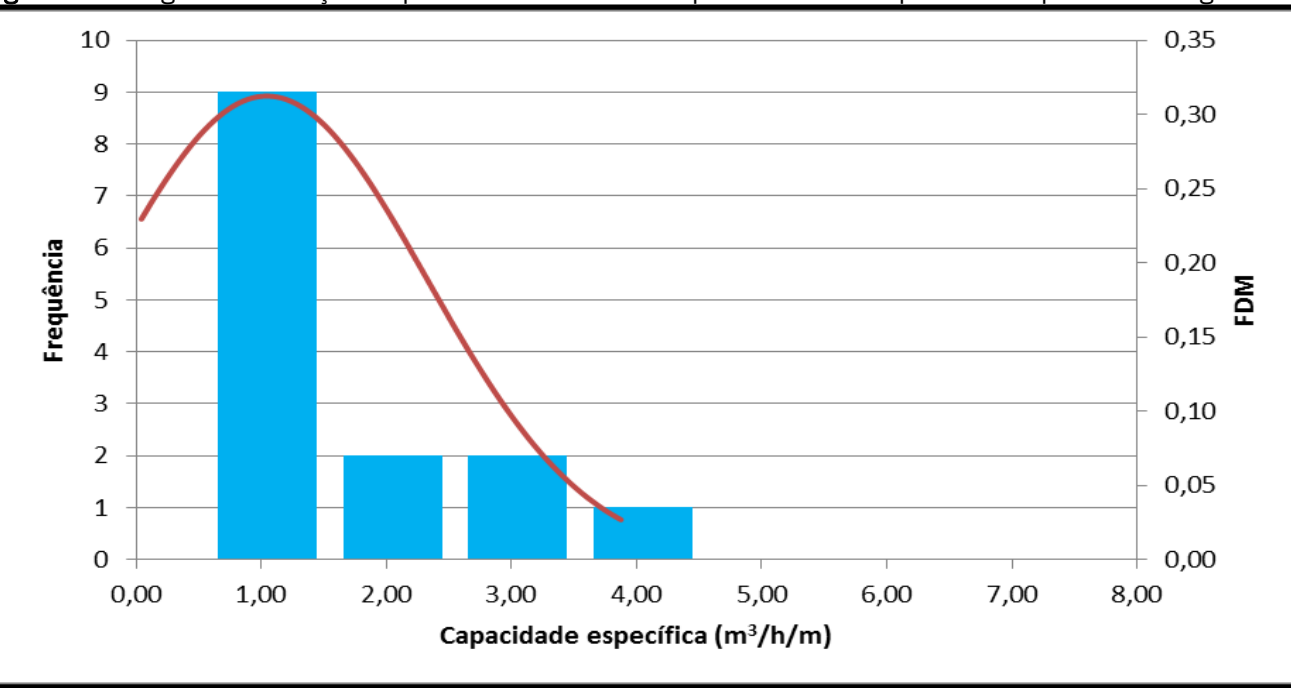

Figura 9 - Área em coloração cinza representa valor de capacidade específica superior a $1 \mathrm{~m} 3 / \mathrm{h} / \mathrm{m}$, sendo considerada produtiva pela análise de favorabilidade. Pontos em preto são os poços com dados de vazão, nível estático e nível dinâmico

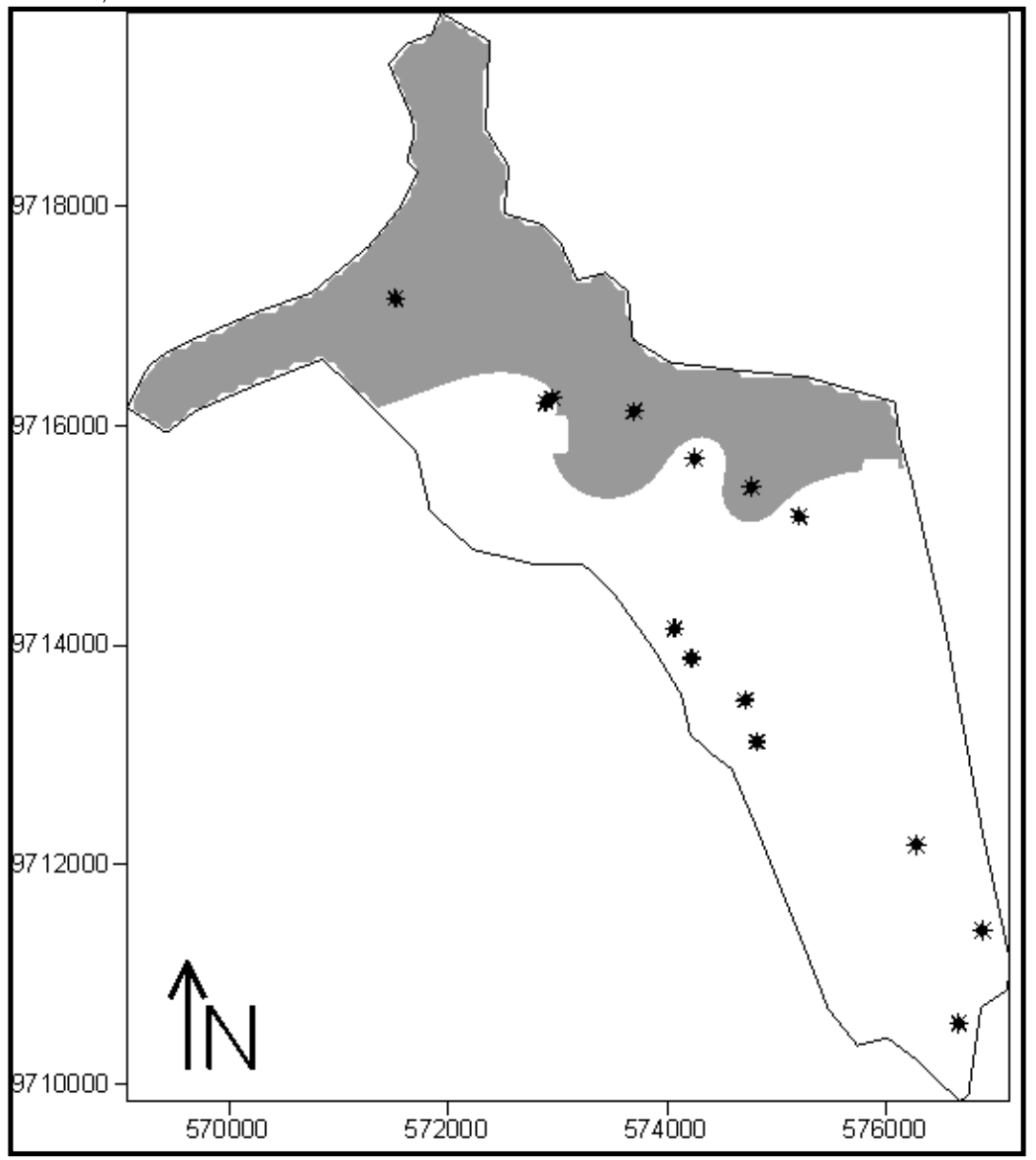


Na Figura 9, as áreas consideradas produtivas estão localizadas por toda a porção norte da área de pesquisa; por outro lado, as porções centro e sul, podem ser caracterizadas pelos baixos valores de capacidade específica.

O mapeamento de áreas produtivas será utilizado para correlacionar com os mapas de probabilidade de ocorrência de arenitos do modelo geológico, sendo possível verificar a maior presença de arenitos a norte da área pesquisada.

Com base na profundidade dos poços com dados de capacidade específica, foi elaborado o gráfico da distribuição dos poços em função da capacidade específica e da profundidade (Figura 10). Nota-se que poços entre 100 e $150 \mathrm{~m}$ de profundidade apresentam tanto valores altos $(3,92 \mathrm{~m} 3 / \mathrm{h} / \mathrm{m})$ como baixos $\left(0,05 \mathrm{~m}^{3} / \mathrm{h} / \mathrm{m}\right)$ de capacidade específica, não sendo possível encontrar uma correlação entre profundidade e produtividade do poço para este intervalo.

Os poços mais profundos (entre 160 e $180 \mathrm{~m}$ ) apresentaram baixos valores de capacidade específica, ou seja, o P-08 possui $0,18 \mathrm{~m}^{3} / \mathrm{h} / \mathrm{m}$, enquanto o P-01 apresenta $0,33 \mathrm{~m} 3 / \mathrm{h} / \mathrm{m}$.

O modelo geológico indicou que, para a região do P-08, em maiores profundidades, há uma maior probabilidade de ocorrência de rochas argilosas que coincidem com a baixa produtividade deste poço.

No entanto, o P-01 está localizado em região com presença de arenitos em maiores profundidades e este baixo valor de capacidade específica pode estar associado ao perfil construtivo do mesmo ou lentes de argila pontuais não identificadas no modelo geológico 3D.

Figura 10 - Gráfico de dispersão entre profundidade e produtividade dos poços

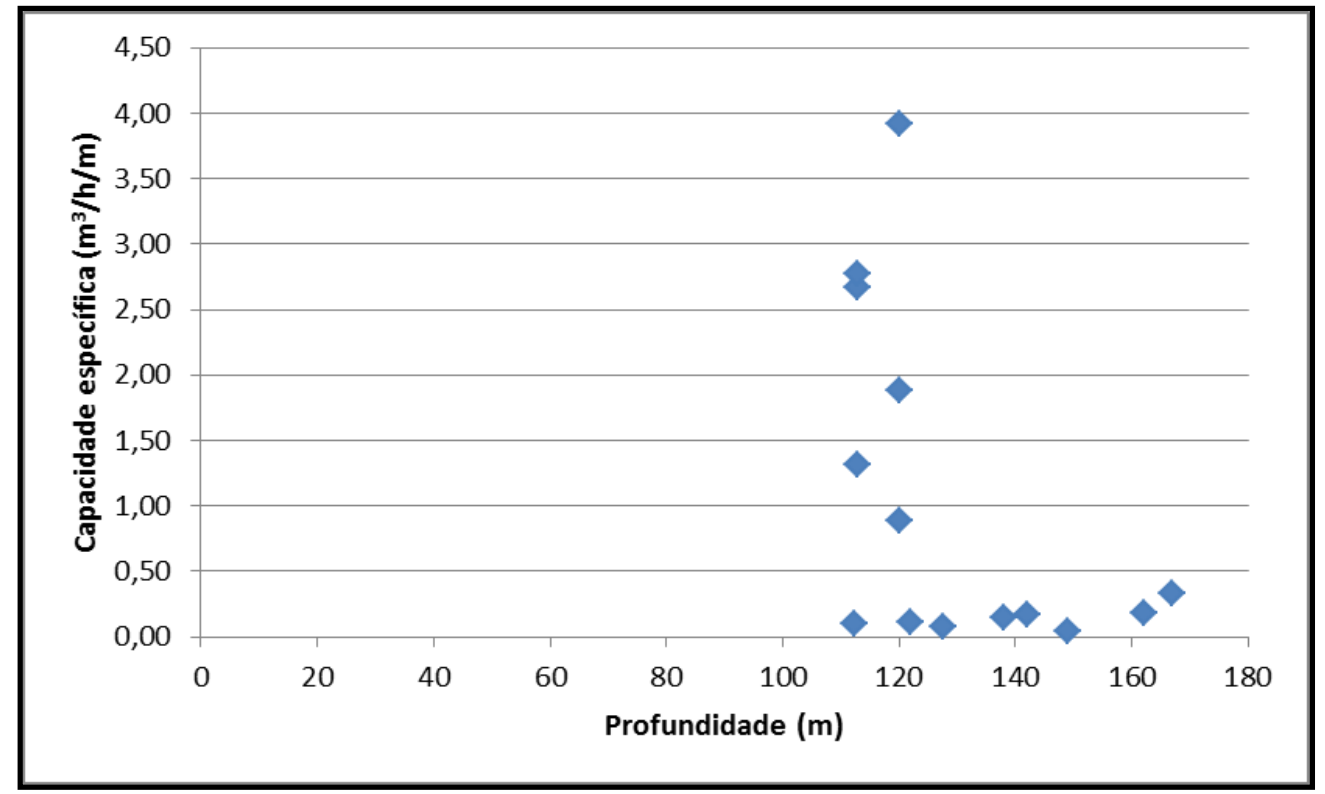

Essa variação de produtividade observada na Figura 10 significa que, mesmo os arenitos estando em profundidades maiores em praticamente toda a área de pesquisa, a profundidade do poço não é garantia de alta produtividade. A produtividade pode estar relacionada também com outros fatores, por exemplo, perfil construtivo do poço, principalmente posicionamento em subsuperfície das seções filtrantes, fatores geomorfológicos e áreas de recarga e descarga do aquífero.

\subsubsection{Mapa de favorabilidade}

A definição de mapa de favorabilidade envolve a análise de dados espaciais que visam à predição da ocorrência de mine ralizações, no caso deste trabalho, da ocorrência de reservatórios de água subterrânea.

Por serem variáveis discretas, a análise se inicia com a atribuição do valor 1 na intersecção das áreas consideradas produtivas com as feições definidas nos mapas de espessura, porcentagem e média das probabilidades de ocorrência de arenitos. E valor zero quando não há intersecção. Foram utilizadas todas as variáveis descritas (porcentagem de arenitos, espessura de arenitos e médias das probabilidades de ocorrência de arenitos), uma vez que os valores de contraste foram superiores a 0,5 (Tabela 3).

Tabela 3 - Pesos e valores de contraste para os dados originais das variáveis utilizadas

\begin{tabular}{lccc}
\multicolumn{1}{c}{ Variáveis Utilizadas } & $\mathbf{W}^{+}$ & $\mathbf{W}^{-}$ & Contraste \\
\hline Porcentagem de arenitos & 3,73 & $-1,26$ & 4,98 \\
Espessura de arenitos & 0,94 & $-0,45$ & 1,38 \\
Média P25 & 1,75 & $-0,81$ & 2,57 \\
Média P50 & 2,13 & $-1,16$ & 3,29 \\
Média P75 & 1,57 & $-1,12$ & 2,69 \\
\hline
\end{tabular}


A probabilidade posterior foi então calculada através da soma dos pesos das variáveis para cada célula, mais a probabilidade a priori (Equação 4). Os resultados obtidos de cada cé lula foram plotados em mapa, que apresenta as áreas mais favoráveis à exploração de água subterrânea correspondente aos maiores valores de probabilidade posterior (Figura 11).

Figura 11 - Favorabilidade hidrogeológica bayesiana para a área de estudo Complexo de Ponta da Madeira/ São Luís - MA

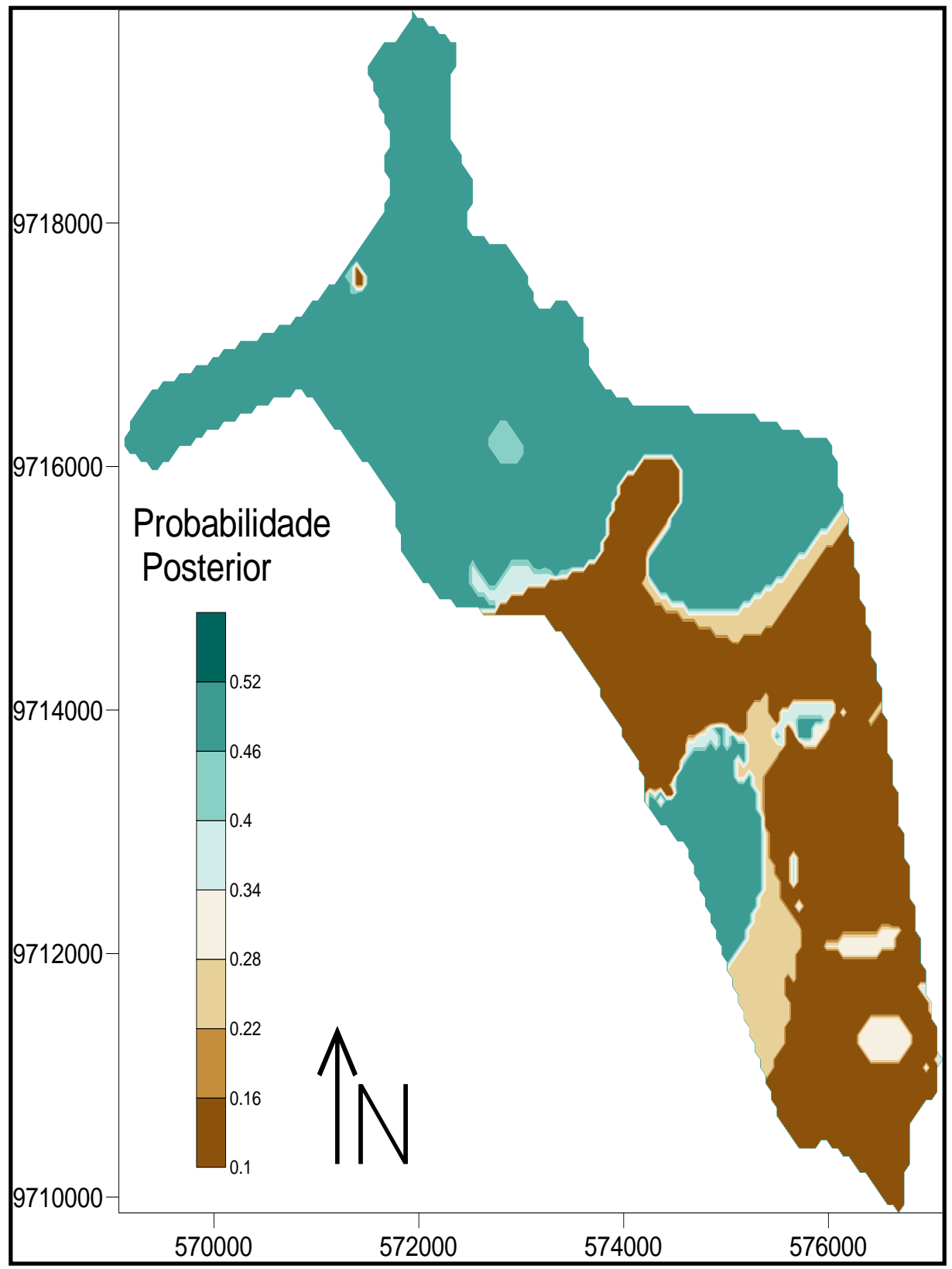


É possível observar que as áreas favoráveis à exploração de água subterrânea apresentam elevados valores de probabilidade posterior.

Para o cálculo dos pesos ( $w+$ e w-) das variáveis selecionadas (espessura, porcentagem e média das probabilidades de ocorrência de arenitos) foi utilizado o algoritmo proposto por Bonham-Carter (1994), conforme Equação 3.

Estes pesos são os atributos mais importantes na análise de favorabilidade, pois quanto maior for a diferença entre $w+e$ w- ou o contraste " $C$ ", mais correlacionável é a variável com a área de maior capacidade específica (BONHAM-CARTER, 1994). Os valores de contraste para os dados originais estão presentes na Tabela 3.

Situação de descarte de alguma variável ocorreria se os pesos apresentassem valores de contaste próximos a zero. Isso comprova que as variáveis utilizadas para a análise de favorabilidade podem ser correlacionadas isoladamente com as áreas mais produtivas.

O melhor valor de contraste é obtido pela variável porcentagem de arenitos, com valor de 4,98. Os demais valores de contraste para os mapas de espessura e médias das probabilidades de ocorrência de arenitos são positivos e inferiores ao da porcentagem de arenitos, indicando, para todas as variáveis analisadas, boa correlação com as áreas produtivas.

A porcentagem de arenitos e os valores médios de P50 são as variáveis que apresentam a maior correlação com a produtivi-

dade dos poços. Por outro lado, as informações presentes no mapa de espessura de arenitos têm pouca correspondência com a distribuição da capacidade específica.

Ao comparar o mapa de capacidade específica (áreas consideradas produtivas) com o mapa de porcentagem de arenitos, é possível observar que este último apresenta altos valores na região norte e baixos nas porções central e sul, o que corresponde a uma boa correlação com as áreas de alto valor de capacidade específica.

O oposto pode ser verificado no mapa de espessura de arenitos, no qual é possível verificar altos valores de espessuras, praticamente, na área toda e, por isso, apresenta um baixo valor de contraste.

A baixa correlação entre o mapa de espessuras de arenitos e o mapa de áreas produtivas pode ser explicada pelo posicionamento dos filtros dos poços. O mapa de espessura considera a espessura total de arenitos, enquanto que a capacidade específica leva em conta o intervalo onde a seção filtrante de cada poço está posicionada em subsuperfície.

Portanto, o mapa de espessura de arenitos pode ter superestimado a capacidade real dos reservatórios ou os projetos construtivos dos poços podem não ter considerado a potencialidade das regiões com alta espessura de arenitos, principalmente, em maiores profundidades.

Como exemplo, o poço P-10B está localizado numa porção da região de pesquisa com alto valor de espessura de arenito (entre 58 e $62 \mathrm{~m}$ ), porém possui baixa capacidade específica $\left(0,10 \mathrm{~m}^{3} / \mathrm{h} / \mathrm{m}\right)$ e, consequentemente, não está inserido em áreas consideradas produtivas.
Analisando-se com mais detalhe o perfil construtivo desse poço, nota-se que os filtros estão posicionados em intervalos distintos e aleatórios, que somados resultam em $40 \mathrm{~m}$ de arenitos.

Dessa forma, o projeto construtivo do poço não considerou a maior potencialidade dessa região em função da espessura de arenito, o que pode ter ocasionado uma perda de $22 \mathrm{~m}$ de espessura de rocha reservatório e consequentemente baixa capacidade específica para o poço.

Outro fator geológico para essa baixa correlação seria relacionado à diagênese nos arenitos; este aspecto não foi analisado neste trabalho. Com o aumento da profundidade pode ocorrer o aumento da salinidade da água, favorecendo a cimentação e não a dissolução, além disso, nas camadas superficiais da área de pesquisa há um predomínio de argilitos.

No mapa de favorabilidade (Figura 10), a maior probabilidade de sucesso na exploração das águas subterrâneas está localizada na porção norte da área pesquisada e, secundariamente, as regiões centro-leste e sudoeste.

As áreas mais favoráveis à exploração apresentam as maiores porcentagens de arenito e as maiores probabilidades de ocorrência de rochas reservatório, bem como, conforme os dados de nível estático, possuem baixo nível potenciométrico, indicando que os poços utilizados na pesquisa captam água tanto de camadas superficiais como mais profundas do aquífero ltapecuru.

\section{CONCLUSÕES}

Levando em consideração apenas as variáveis litologia, vazão, nível estático e nível dinâmico, a análise de favorabilidade realizada para o aquífero Itapecuru em região costeira conseguiu identificar áreas mais favoráveis para a exploração das águas subterrâneas e, consequentemente, aumentou as possibilidades de oferta de água para uma região altamente demandante deste recurso natural.

A condição de alta variabilidade das informações referentes às descrições litológicas dos perfis dos poços da base de dados, como também a distribuição espacial irregular dos mesmos (maior concentração de informação na porção leste da área), podem contribuir para aumentar o grau de incerteza do modelo geológico 3D gerado, o qual pode gerar possíveis erros no mapa de favorabilidade. No entanto, vale ressaltar que o modelo é originado pelas informações de campo dos poços e o mapa de favorabilidade foi validado com valores positivos de contraste.

Os dados e resultados apresentados nesta pesquisa são uma primeira tentativa de aplicar o método de favorabilidade bayesiana para a exploração de forma mais planejada das águas do aquífero Itapecuru na ilha do Maranhão, sendo que as dificuldades encontradas no decorrer do trabalho indicaram ser necessário um melhor desenvolvimento na definição dos critérios de cut off para a variável capacidade específica na definição de áreas produtivas.

Com isso, é recomendado que trabalhos posteriores utilizem novas variáveis relacionadas à caracterização da rocha reservatório, como transmissividade e condutividade hidráulica, e também realizem a definição de classes no caso de variáveis discretas, por exemplo, características hidrográficas. 
Além disso, é importante a inserção da variável salinidade no mapa de favorabilidade a fim de se avaliar a influência da cunha salina no aquífero Itapecuru.

Dependendo dessa influência, o recurso hídrico subterrâneo pode não ser utilizado para uso industrial ou portuário em função dos padrões de qualidade, que podem ser prejudicados pela influência da água do mar.

\section{REFERÊNCIAS}

ALMEIDA, F.F.M. Origem e evolução da Plataforma Brasileira. Rio de Janeiro: DNPM/DGM. Boletim, 241, 1967.

ALMEIDA, F.F.M.; BRITO NEVES, B.B. DE; FUCK, R.A. Províncias estruturais brasileiras. In: SIMPÓSIO DE GEOLOGIA DO NORDESTE, 8, Campina Grande. [Atas...]. Campina Grande: SBG, 499 p. il. Boletim do Núcleo Nordeste da SBG, 6, p. 363-391, 1977.

ARAÚJO C.C.; MACEDO, A.B. Multicriteria geologic data analysis for mineral favorability mapping: application to a metal sulphide mineralized area Ribeira Valley Metallogenic Province, Brazil. Nat. Res. Research, v.11, p.29-43, 2002. https://doi.org/10.1023/A:1014235703541

BONHAM-CARTER, G. F. Geographic information systems for geoscientists: modelling with GIS. Computer methods in the geosciences. 1. Edition. v. 13. Canada, Pegamon Press, 398p. $1994 . \quad$ https://doi.org/10.1016/B978-0-08-0418674.50006-0

FELGUEIRAS C.A.; DRUCK, S.; MONTEIRO, A.M.V. Análise espacial de superfícies: o enfoque da geoestatística por indicação. Ministério da Ciência e Tecnologia/ INPE, 2002. 25 p.

FREEZE, A.R.; CHERRY, J.A. Água subterrâneas. Tradução de Everton de Oliveira [et al.]; Everton de Oliveira (Coord.). - São Paulo (SP): Everton de Oliveira. 698 p.: il; 30cm, 2017.

GOOVAERTS P. Geostatistics for natural resources evaluation. Oxford University Press, 483 pp. 1997.

HARRIS, D.V.; ZURCHER, L.; STANLEY, M.; MARLOW, J.; PAN, G. A comparative analysis of favorability mappings by weights of evidence, probabilistic neural networks, discriminant analysis and logistic regression. Natural Resources Research, v.12, n.4, p.241-255, 2003. https://doi.org/10.1023/B:NARR.0000007804.27450.e8

HIRATA, R.; ZOBY, J.L.G; OLIVEIRA, F.RI. Água Subterrânea: reserva estratégica ou emergencial. In: BICUDO, C. E. M. et al. (orgs.). Águas no Brasil: análises estratégicas. Academia Brasileira de Ciência, São Paulo, p.149-161, 2010.

JOURNEL, A.G. The place of non-parametric geostatistics. In: G. Verly et al. (Ed.). Geostatistics for Natural Resources Characterization, Part I. D. Reidel Publishing Co., Dordrecht, p.307335.1984. https://doi.org/10.1007/978-94-009-3699-7_19

KLEIN, E.L,; SOUSA, C.S.; VASQUEZ, M.L.; LOPES, E.C.S.; TEIXEIRA, S.G.; OLIVEIRA, J.K.M.; MOURA, E.M.; LEÃO M.H.B. Mapa Geológico e Recursos Minerais do Estado do Maranhão. In: KLEIN, E.L.; SOUSA, C.S. (organizadores) Geologia e Recursos Minerais do Estado do Maranhão: Sistema de Informações Geográficas - SIG, Escala 1:750.000. Belém: CPRM, 2012.

LEE, S.; KIM, Y.S.; OH, H.J. Application of a weights-of-evidence method and GIS to regional groundwater productivity potential mapping. J. Environ. Manage. v.96, n.1, p.91-105, 2012. https://doi.org/10.1016/i.jenvman.2011.09.016
LIU C.W; JANG,C.S; LIAO, C.M. Evaluation of arsenic contamination potential using indicator kriging in the Yun-Lin aquifer (Taiwan). Science of the Environment, v.321, p.173-188, 2004. https://doi.org/10.1016/j.scitotenv.2003.09.002

MADRUCCI, V. Prospecção de água subterrânea em terreno cristalino utilizando-se análise integrada de dados de sensoriamento remoto, geofísicos e técnicas de geoprocessamento, região de Lindóia, SP. São Paulo. Tese (Doutorado) - Instituto de Geociências - USP, 2004.

MADRUCCI, V; TAIOLI, F; ARAÚJO, C.C. Groundwater favorability map using GIS multicriteria data analysis on crystalline terrain, São Paulo State, Brazil. Journal of Hydrology, v.357, p.153173, 2008. https://doi.org/10.1016/i.jhydrol.2008.03.026

MOREAUX, M.; REYNAUD, A. Urban freshwater needs and spatial cost externalities for coastal aquifers: A theoretical approach. Regional Science and Urban Economics, v. 36, n.2, p.163-186, 2006. https://doi.org/10.1016/j.regsciurbeco.2005.09.002

RAINES, G.L., Evaluation of weights of evidence to predict epithermal-gold deposits in the Great basin of the Western United States. Natural Resources Research, v.8, n.4, p. 257-276, 1999. https://doi.org/10.1023/A:1021602316101

REMY, N., BOUCHER, A. WU, J. Applied Geostatistics with SGeMS. Cambridge University Press, 2004. 264p

ROSTIROLLA, S. P. Avaliação de favorabilidade em exploração: um enfoque metodológico. Tese (Doutorado) - IGCE/UNESP. Rio Claro 164p, 1996.

ROSTIROLLA, S. P. Alguns aspectos da avaliação de favorabilidade em geologia exploratória. Ver.Brás. Geoc., v. 27, n.4, p.327-338, 1997. https://doi.org/10.25249/03757536.1997327338

SANTOS, L.C.A; LEAL, A.C.. Gerenciamento de recursos hídricos no Estado do Maranhão - Brasil. Observatorium: Revista Eletrônica de Geografia, v.5, n.13, p.39-65, jun. 2013.

TEIXEIRA, S. G.; SOUZA FILHO, P. W. M. Mapeamento de ambientes costeiros tropicais (Golfão Maranhense, Brasil) utilizando imagens de sensores remotos orbitais. Revista Brasileira de Geofísica, v.27, p.69-82, 2009. https://doi.org/10.1590/S0102-261X2009000500006

VALE. Programa de Gestão de Recursos Hídricos. 2012.

VIDAL, A. C. Estudo hidrogeológico do Aqüífero Tubarão na área de afloramento da porção central do Estado de São Paulo. Tese (Doutorado) - IGCE/UNESP. Rio Claro-SP, 2002. $109 \mathrm{p}$.

VIDAL, A.C.; ROSTIROLLA, S.P.; CHANG, C.H.; MARTINI, M.L. Estudo da relação entre lineamentos estruturais e a exploração de água subterrânea por meio da análise de favorabilidade. Águas Subterrâneas, v.20, n.2, p.27-38, 2006. https://doi.org/10.14295/ras.v20i2.10436

WALM. Estudos hidrogeológicos para a verificação da viabilidade de explotação de água subterrânea do aquífero profundo na área do complexo de ponta da madeira, São Luís, MA, 2012. 